\title{
A Three-Port Acoustic Lattice Model for Piezoelectric Transducers Containing Opposing Zones of Polarization
}

\author{
S N Ramadas*, G Hayward*, R L O’Leary*, T McCunnie*, A J Mulholland $\dagger$, \\ A Troge $\ddagger$, R A Pethrick $\ddagger$, D Robertson§, and V Murray§; \\ $*$ Centre for Ultrasonic Engineering, $\dagger$ Department of Mathematics, $\$$ Department of Pure and Applied \\ Chemistry, Strathclyde University, Glasgow, Scotland; \\ §Alba Ultrasound Ltd, 100 Borron Street, Glasgow G4 9XG, Scotland
}

\begin{abstract}
Inversion Layer Transducers (ILT) have attracted considerable interest in the recent past, due to the wide bandwidth and even harmonic sensitivity. This paper presents a new threeport lattice model for ILT devices. Based on linear systems theory, a discrete bi-directional lattice is used to describe the mechanical wave propagation and continuous transfer function to represent the electrical parameter. The mathematical formulation for an ILT configuration, and a straightforward physical interpretation of the lattice model is presented. A selection of experimental and simulation results are included to demonstrate the feasibility of the technique.
\end{abstract}

\section{INTRODUCTION}

$\mathrm{T}_{\mathrm{r}, \mathrm{sen}}$ HE acoustic lattice concept, whereby individual propagation layers may be represented as discrete, bidirectional lattices, offers an efficient method for simulation of thickness mode ultrasonic transducers, while at the same time promoting physical understanding of the electromechanical behaviour. Inversion Layer Transducers [3], in the form of two or more active, piezoelectrically opposed regions, have attracted considerable interest in the recent past, due to the potential for wide bandwidth and even harmonic sensitivity. However, optimization of device performance, including signal to noise ratio (SNR), is not straightforward and improved analytical techniques are required. This work describes a new three-port lattice model to design and optimize ILT devices.

Section II describes the key characteristic and formulation of the lattice model. This is followed by analysis of transducer structure using the model presented. The first of these is the implementation of a front face inversion layer (FFIL) configuration with multiple matching layers. Different filter design techniques are used to construct the matching layer

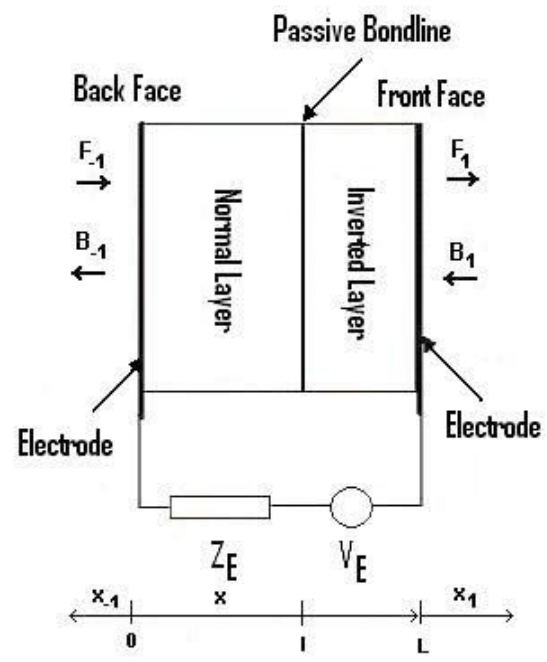

Fig. 1. An inversion layer (IL) transducer.

profiles in order to maximize device bandwidth and which may be further improved by standard computer optimization procedures. Secondly, the lattice model is used to determine the noise generated within an ILT. The importance of correct design is demonstrated in order to maximise SNR over the available bandwidth. Comparisons with experimental measurements on an example device demonstrate the validity of the technique.

\section{LATTICE MODEL FOR ILT}

\section{A. Fundamental Theory}

A lattice model for ILT devices is developed in a similar manner to the three-port systems model developed by Jackson [1] for conventional thickness mode devices. Consider the layered system shown in Figure 1, which depicts a two layered system with the inversion layer at the front face. The transducer is 
connected to an arbitrary electrical load $\left(Z_{E}\right)$ in series with a Thevenin equivalent voltage source $\left(V_{E}\right)$. The piezoelectric structure is positioned between two semi-infinite media and all media are assumed to be lossless and hence can be represented by their real specific acoustic impedances.

For plane wave propagation in the thickness direction, the expressions for particle displacement and force within a piezoelectric medium [2] are given as follows:

$$
\begin{aligned}
& \xi \mathrm{t}=\mathrm{A}_{\mathrm{ft}} \mathrm{e}^{-\mathrm{s}(\mathrm{xt} / \mathrm{vt})}+\mathrm{B}_{\mathrm{bt}} \mathrm{e}^{\mathrm{s}(\mathrm{xt} / \mathrm{vt})} \\
& \Gamma=\mathrm{sZ}_{\mathrm{t}}\left\{-\mathrm{A}_{\mathrm{ft}} \mathrm{e}^{-\mathrm{s}(\mathrm{xt} / \mathrm{vt})}+\mathrm{B}_{\mathrm{bt}} \mathrm{e}^{\mathrm{s}(\mathrm{xt} / \mathrm{vt})}\right\} \pm \mathrm{hQ}_{\mathrm{t}}
\end{aligned}
$$

Where $f, b$ represent forward and backward travelling wave components.

At the interfaces between two adjacent layers, there is continuity of particle displacement and force. Applying these boundary conditions, we get the following relations

$$
\begin{aligned}
& \left(-\mathrm{F}_{-10}+\mathrm{B}_{-10}\right) / \mathrm{Z}_{-1}=\left(-\mathrm{F}_{\mathrm{t} 0}+\mathrm{B}_{\mathrm{t} 0}\right) / \mathrm{Z}_{\mathrm{t}} \\
& \left(-\mathrm{F}_{\mathrm{tl}}+\mathrm{B}_{\mathrm{tl}}\right)=\left(-\mathrm{F}_{\mathrm{t}^{\prime} 0}+\mathrm{B}_{\mathrm{t}^{\prime} 0}\right) \\
& \left(-\mathrm{F}_{\mathrm{t}^{\prime} \mathrm{l}^{\prime}}+\mathrm{B}_{\mathrm{t}^{\prime} \mathrm{l}^{\prime}}\right) / \mathrm{Z}_{\mathrm{t}}=\left(-\mathrm{F}_{10}+\mathrm{B}_{10}\right) / \mathrm{Z}_{1} \\
& \mathrm{~F}_{-10}+\mathrm{B}_{-10}=\mathrm{F}_{\mathrm{t} 0}+\mathrm{B}_{\mathrm{t} 0}-\mathrm{hQ}_{\mathrm{t}} \\
& \mathrm{F}_{\mathrm{tl}}+\mathrm{B}_{\mathrm{tl}}-\mathrm{hQ}_{\mathrm{t}}=\mathrm{F}_{\mathrm{t}^{\prime} 0}+\mathrm{B}_{\mathrm{t}^{\prime} 0}+\mathrm{hQ}_{\mathrm{t}} \\
& \mathrm{F}_{\mathrm{t}^{\prime} \mathrm{l}^{\prime}}+\mathrm{B}_{\mathrm{t}^{\prime} \mathrm{l}^{\prime}}+\mathrm{hQ}_{\mathrm{t}}=\mathrm{F}_{10}+\mathrm{B}_{10}
\end{aligned}
$$

Equation 3 can be rearranged in a matrix form, as shown below

$$
\begin{aligned}
& {\left[\begin{array}{c}
\mathrm{B}_{-10} \\
\mathrm{~F}_{\mathrm{t} 0}
\end{array}\right]=\left[\begin{array}{cc}
\mathrm{R}_{-1} & 1-\mathrm{R}_{-1} \\
1+\mathrm{R}_{-1} & -\mathrm{R}_{-1}
\end{array}\right]\left[\begin{array}{c}
\mathrm{F}_{-10} \\
\mathrm{~B}_{\mathrm{t} 0}
\end{array}\right]} \\
& +\frac{\mathrm{hQ}(\mathrm{t})}{2}\left[\begin{array}{c}
\left(1-\mathrm{R}_{-1}\right) \\
-\left(1+\mathrm{R}_{-1}\right)
\end{array}\right] \\
& {\left[\begin{array}{c}
\mathrm{F}_{10} \\
\mathrm{~B}_{\mathrm{t}^{\prime} \mathrm{l}^{\prime}}
\end{array}\right]=\left[\begin{array}{cc}
\mathrm{R}_{1} & 1-\mathrm{R}_{1} \\
1+\mathrm{R}_{1} & -\mathrm{R}_{1}
\end{array}\right]\left[\begin{array}{c}
\mathrm{B}_{10} \\
\mathrm{~F}_{\mathrm{t}^{\prime} \mathrm{l}^{\prime}}
\end{array}\right]} \\
& +\frac{\mathrm{hQ}(\mathrm{t})}{2}\left[\begin{array}{c}
\left(1-\mathrm{R}_{1}\right) \\
-\left(1+\mathrm{R}_{1}\right)
\end{array}\right] \\
& \mathrm{B}_{\mathrm{t} 1}=\mathrm{B}_{\mathrm{t}^{\prime} 0}+\mathrm{hQ}_{\mathrm{t}} \\
& \mathrm{F}_{\mathrm{t}^{\prime} 0}=\mathrm{F}_{\mathrm{tl}}-\mathrm{hQ}_{\mathrm{t}}
\end{aligned}
$$

Where $\mathrm{R} 1$ and $\mathrm{R}_{-1}$ are the reflection coefficients for the waves of force entering the two piezoelectric media. Also, the forward and backward travelling waves in each piezoelectric layer are given by the following Equation,

$$
\left[\begin{array}{c}
\mathrm{F}_{\mathrm{il}_{\mathrm{i}}} \\
\mathrm{B}_{\mathrm{il}_{\mathrm{i}}}
\end{array}\right]=\left[\begin{array}{cc}
\mathrm{e}^{-\mathrm{sT}_{\mathrm{i}}} & 0 \\
0 & \mathrm{e}^{\mathrm{sT}_{\mathrm{i}}}
\end{array}\right]\left[\begin{array}{c}
\mathrm{F}_{\mathrm{i} 0} \\
\mathrm{~B}_{\mathrm{i} 0}
\end{array}\right]
$$

Where the subscript i represent the layer number.
Equations 4 and 5 describe the system lattice for a front face ILT. It is now required to obtain the relation between source voltage and charge and incorporate this into the model. The overall voltage across the piezoelectric transducer [3] is given by

$$
\begin{aligned}
\mathrm{V} & =\mathrm{V}_{\text {Normal }}+\mathrm{V}_{\text {Inverted }} \\
& =-\mathrm{h}\left\{2 \xi_{(\mathrm{x}=1)}-\xi_{(\mathrm{x}=0)}-\xi_{(\mathrm{x}=\mathrm{L})}^{\prime}\right\}+\frac{\mathrm{Q}_{\mathrm{t}}}{\mathrm{C}_{\mathrm{t}}}
\end{aligned}
$$

From Figure 1, $I_{t}=s Q_{t}$ and $V_{t}=V_{E}-I_{t} Z_{E}$. Substituting these in the Equation 6, Qt can be expressed in terms of the drive voltage as

$$
\mathrm{Q}_{\mathrm{t}}=\frac{\mathrm{C}_{\mathrm{t}}}{1+\mathrm{s} \mathrm{Z}_{\mathrm{E}} \mathrm{C}_{\mathrm{t}}}\left(\mathrm{V}_{\mathrm{E}}+\mathrm{h}\left\{2 \xi_{(\mathrm{x}=1)}-\xi_{(\mathrm{x}=0)}-\xi_{(\mathrm{x}=\mathrm{L})}^{\prime}\right\}\right)
$$

Substituting Equation 3 in the previous Equation

$$
\begin{aligned}
\mathrm{Q}_{\mathrm{t}}= & \frac{\mathrm{C}_{\mathrm{t}}}{1+\mathrm{sZ}_{\mathrm{E}} \mathrm{C}_{\mathrm{t}}}\left(\mathrm{V}_{\mathrm{E}}+\frac{\mathrm{h}}{\mathrm{s} \mathrm{Z}_{\mathrm{t}}}\left\{\left(\mathrm{e}^{-\mathrm{st}}-1\right)\right.\right. \\
& \left.\left.\left(\mathrm{F}_{\mathrm{t}^{\prime} \mathrm{l}}+\mathrm{B}_{\mathrm{t}^{\prime} \mathrm{L}}\right)+\left(1-\mathrm{e}^{-\mathrm{st}}\right)\left(\mathrm{F}_{\mathrm{t} 0}+\mathrm{B}_{\mathrm{tl}}\right)\right\}\right)
\end{aligned}
$$

However, it is easier to measure voltage across the transducer than the charge on the electrodes. That is,

$$
\begin{aligned}
\mathrm{V}_{\mathrm{t}}= & \frac{\mathrm{V}_{\mathrm{E}}}{1+\mathrm{sZ}_{\mathrm{E}} \mathrm{C}_{\mathrm{t}}}-\frac{\mathrm{hZ}_{\mathrm{E}} \mathrm{C}_{\mathrm{t}}}{\mathrm{Z}_{\mathrm{t}}\left(1+\mathrm{s} \mathrm{Z}_{\mathrm{E}} \mathrm{C}_{\mathrm{t}}\right)}\left\{\left(\mathrm{e}^{-\mathrm{st}}-1\right)\right. \\
& \left.\left(\mathrm{F}_{\mathrm{t}^{\prime} \mathrm{l}}+\mathrm{B}_{\mathrm{t}^{\prime} \mathrm{L}}\right)+\left(1-\mathrm{e}^{-\mathrm{st}}\right)\left(\mathrm{F}_{\mathrm{t} 0}+\mathrm{B}_{\mathrm{tl}}\right)\right\}
\end{aligned}
$$

Equation 9 along with Equations 4 and 5 can be represented in block diagram format as shown in Figure 2, which is a three port system model with $\mathrm{F}_{-10}, \mathrm{~B}_{10}$ and $\mathrm{V}_{\mathrm{E}}$ as the input ports and $\mathrm{F}_{10}$, $\mathrm{B}_{-10}$ and $\mathrm{V}_{\mathrm{t}}$ forming the output ports.

\section{B. Advantages of three port lattice model:}

The main advantage of the proposed model is the lattice formulation, which facilitates the understanding of the fundamental physics behind a transduction process of an ILT device. Physical interpretation of an ILT lattice can be carried out in similar fashion to [1] and the contribution of the inverted layer can be readily identified.

Being a general model that may be used for both transmit and receive cases, the model can be extended to a general multilayer case, with $\mathrm{m}$ matching and $\mathrm{n}$ backing layers, using existing literature [1].

The three port acoustic model mentioned in the previous section can be implemented readily in MATLAB/Simulink environment [7]. The PSpice SLPS interface [5] can be used to link the MATLAB/Simulink system simulator and the PSpice A/D electric circuit simulator [6]. Thus providing a modeling environment that combines the advantages of each of these simulators. 


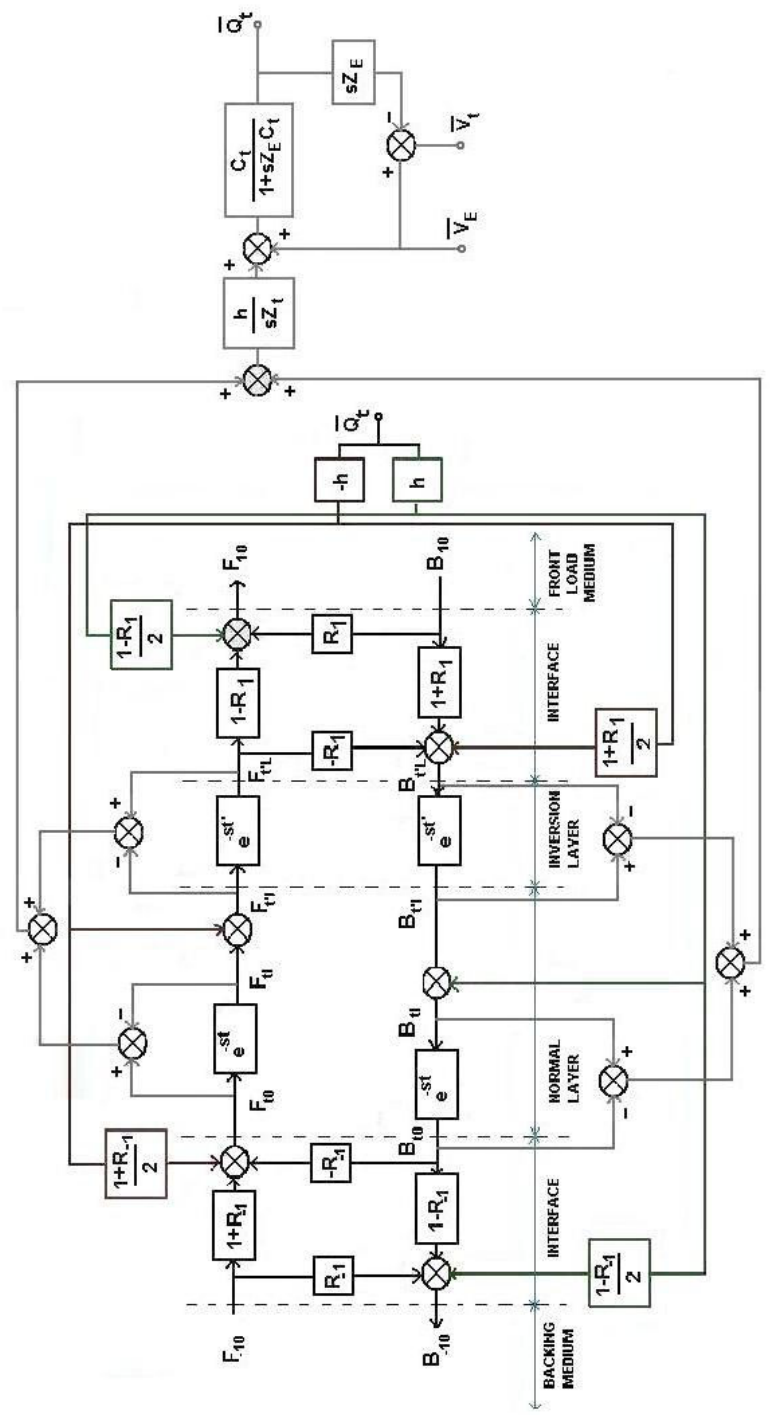

Fig. 2. Lattice model for a FFIL device including electrical section of the system

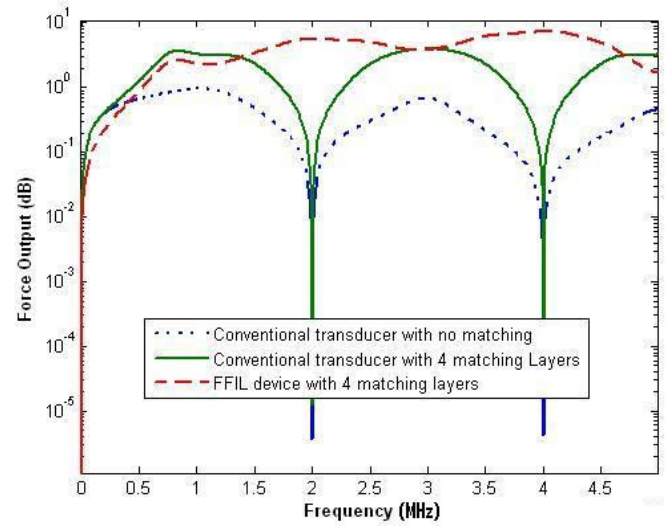

Fig. 3. Comparisonal analysis of a matched FFIL and conventional device

\section{A. Bandwidth Improvement using Multiple Matching Layers}

Using the mathematical model described in the earlier section, a FFIL transducer, denoted device $\mathrm{A}$, with a nominal fundamental thickness mode of $1 \mathrm{MHz}$, comprising $40 \%$ volume fraction PZT5A (Ferroperm, Kvistgard, Denmark) and CY1301/HY1300 epoxy (Vantico Ltd, Duxford, UK) was designed. Various acoustic matching schemes were derived to match the impedance of the above transducer (13.6MRayl) to water load (1.5MRayl), using well established filter design techniques [8].

Two examples, one giving a maximally flat and a second exhibiting equal-ripple transducer bandwidth are shown in Table I. The predicted impulse response and device operational impedance of a four layer, matched FFIL transducer (equal-ripple scheme \#1 in Table I), along with comparison to a conventional thickness mode device of similar specification is shown in Figure 3 . It can be seen clearly that the presence of the inverted layer promotes the even harmonic activity in the device, and by carefully selecting a matching scheme, a transducer with much improved operational bandwidth and sensitivity can be achieved.

Device A was manufactured using the Chebyshev equalripple scheme 2 detailed in Table I. The salient properties of the matching layer materials measured at $500 \mathrm{kHz}$ are shown in Table II. Figures 4 and 5 show the experimental and simulated results, respectively. In spite of being a lossless, ideal one dimensional model, the simulated results compare well with the experiment, in identifying the peaks in the transducer response and its overall shape.

\section{B. Noise Model for an ILT Receiver}

An earlier study by one of the authors [4] indicated clearly that

TABLE I

THEORETICAL MATCHING IMPEDANCE(MRAYL) Calculated Using The Filter Design Technique

\begin{tabular}{ccccc}
\multicolumn{5}{c}{ CALCULATED USING THE FILTER DESIGN TECHNIQUE } \\
\hline \hline Layer & 1 & 2 & 3 & 4 \\
\hline Binomial/Maximally Flat & 11.96 & 6.88 & 3 & 1.72 \\
$\begin{array}{c}\text { Chebyshev/ Equal Ripple } \\
\text { Scheme 1 }\end{array}$ & 10.19 & 6.15 & 3.34 & 2.01 \\
$\begin{array}{c}\text { Chebyshev/ Equal Ripple } \\
\text { Scheme 2 }\end{array}$ & 6.46 & 5.1 & 4 & 3.15 \\
\hline \hline
\end{tabular}

TABLE II

Matching Layer Material PRoPerties Measured At 500KHZ

\begin{tabular}{cccc}
\hline \hline & Z(MRayl) & $\begin{array}{c}\text { Density } \\
(\mathrm{Kg} / \mathrm{m} 3)\end{array}$ & $\begin{array}{c}\text { Velocity } \\
(\mathrm{m} / \mathrm{s})\end{array}$ \\
\hline Layer 1 & 6.26 & 2487 & 2519 \\
Layer 2 & 5.16 & 2039 & 2532 \\
Layer 3 & 4.13 & 1829 & 2257 \\
Layer 4 & 3.03 & 1178 & 2568 \\
\hline \hline
\end{tabular}




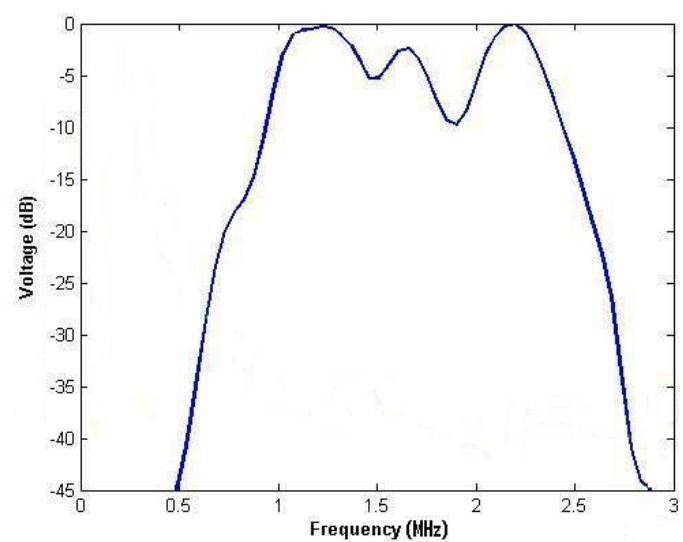

Fig. 4. Experimental pulse echo response in water of device A

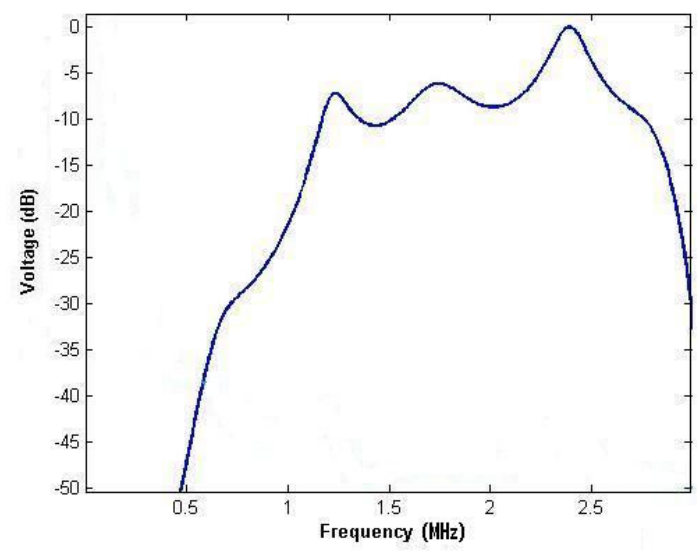

Fig. 5. Simulated FFIL impulse response of device A

transducer noise power spectral density (PSD) is equivalent to the thermal noise produced by the resistive portion of the transducer operational impedance.

A low noise pre-amplifier arrangement with following specification, En $=800 \mathrm{pV} / \sqrt{ } \mathrm{Hz}$, In $=1 \mathrm{pA} / \mathrm{p} \sqrt{ } \mathrm{Hz}, \mathrm{Z}_{\mathrm{IN}}=7 \mathrm{k} \Omega$, a

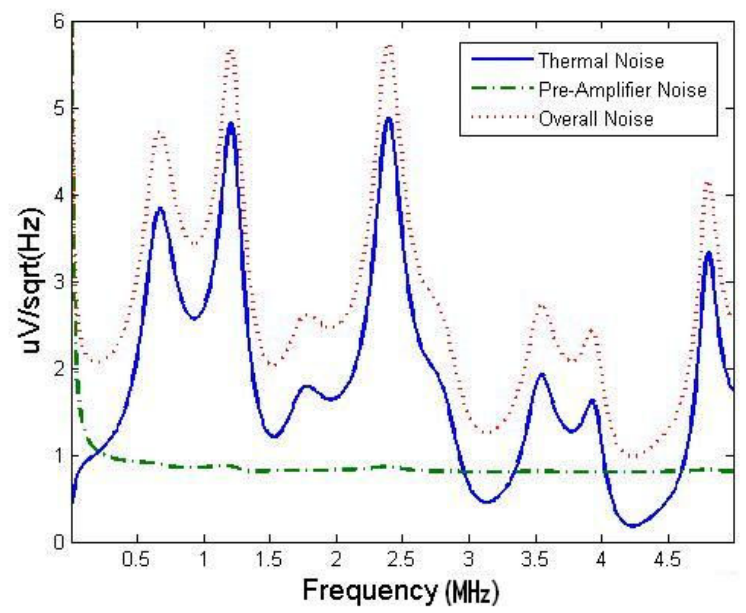

Fig. 6. Noise mechanism within a FFIL receiver flat band pass response across the frequency of interest and a signal gain of $60 \mathrm{~dB}$ was considered for simulation purposes. Based on existing literature [4], a Thevenin equivalent noise model of an ILT including the pre-amplifier stage was developed. The major noise mechanisms within a FFIL receiver are shown in Figure 6. Figure 7 shows the SNR for the FFIL receiver. Major noise contributions occur in the vicinity of the resonant peaks that relate to the fundamental and second harmonic frequencies. The region of maximum SNR are readily

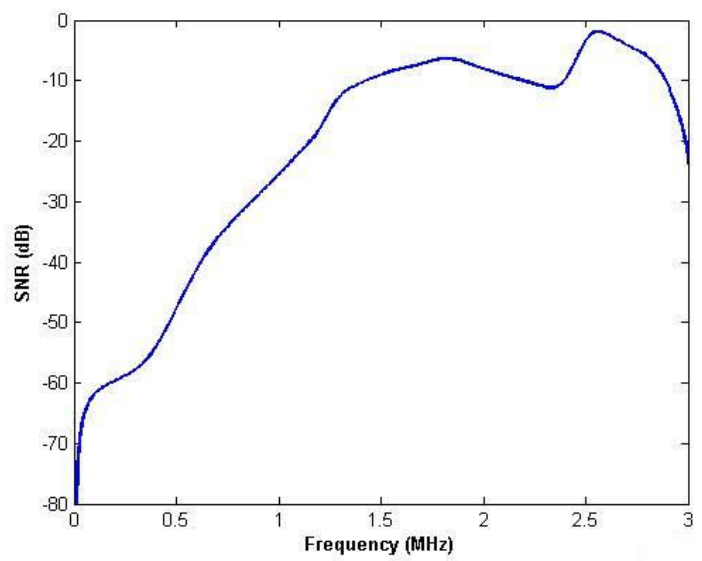

Fig. 7. Simulated FFIL receiver SNR

identified.

\section{CONCLUSION}

A three-port lattice model for ILT devices has been presented long with a straightforward physical interpretation of the lattice Model and the associated advantages. The design of multiple matched FFIL design to improve device bandwidth and SNR is also presented. The experimental and simulation results included compare well and demonstrate the feasibility of the technique.

\section{REFERENCES}

[1] G. Hayward and M. N. Jackson, A Lattice Model of the Thickness - Mode Piezoelectric Transducer, IEEE Trans. on Ultrasonics, Ferroelectrics and Frequency Control, vol. 33, no. 1, pp. 41-50, 1986.

[2] G. K. Lewis, A matrix technique for analyzing the performance of multilayered front matched and backed piezoelectric ceramic transducers, J. Acoust. Soc. Am, pp. 395-416, 1980.

[3] Y. Estanbouli, G. Hayward, S. N. Ramadas and J. C. Barbenel, A Block Diagram Model of the Thickness Mode Piezoelectric Transducer Containing Dual, Oppositely Polarised Piezoelectric Zones, IEEE Trans. on Ultrasonics, Ferroelectrics and Frequency Control, vol. 53, no. 5, pp. 10281036, 2006.

[4] G. Hayward, R. A. Banks and L. B. Russell, A Model for Low Noise Design of Ultrasonic Transducers, Proc. IEEE Ultrasonics Symposium, pp. 971-974, 1995.

[5] Cybernet Systems Co. Ltd., http://www.cybernet.co.jp/slps/

[6] Cadence Design Systems Inc., http://www.cadence.com

[7] The MathWorks, http://www.mathworks.com/

[8] R. E. Collins, Foundations of Microwave Engineering, McGraw-Hill, 1966 